\title{
Visceral leishmaniasis in pregnancy: a case report
}

\author{
Arlene J.M. Caldas ${ }^{a}$ *, Jackson M.L. Costa ${ }^{a}$, Mônica E.A. Gama ${ }^{\text {a }}$, \\ Eduardo A.G. Ramos ${ }^{\mathrm{b}}$, Aldina Barral ${ }^{\mathrm{b}}$ \\ ${ }^{a}$ Department of Pathology, Nucleus of Tropical Pathology and Social Medicine, Federal University of Maranhão, Praça Madre Deus No \\ 2 (Bairro Madre Deus), CEP 65025 560, São Luís, MA, Brazil \\ ${ }^{\mathrm{b}}$ Gonçalo Moniz Research Centre, Oswaldo Cruz Foundation, FIOCRUZ, Bahia, Brazil
}

Received 31 January 2003; received in revised form 17 April 2003; accepted 7 May 2003

\begin{abstract}
Visceral leishmaniasis (VL) is endemic in the island of São Luis, State of Maranhão, Brazil. Despite an increase in the number of VL cases, the frequency of the disease is low among pregnant women. We present here the case of a pregnant woman followed up by our group, who was treated with amphotericin B with excellent outcome.
\end{abstract}

(C) 2003 Published by Elsevier B.V.

Keywords: Visceral leishmaniasis; Leishmania chagasi; Pregnancy

\section{Introduction}

American visceral leishmaniasis (AVL, kalaazar) is endemic in $18(66.7 \%)$ states of Brazil and mainly affects children aged less than 5 years, with clear spreading throughout the country. Most cases have been reported in the north-eastern Brazilian states, including Bahia, Piauí, Ceará and Maranhão (FNS, 1996; Vieira and Coelho, 1998). In Maranhão, the main problem area is its capital São Luís, where $75 \%$ of notified cases are concentrated (Vieira and Coelho, 1998).

The occurrence of VL in Brazil is associated with the precarious socio-economic conditions of

\footnotetext{
* Corresponding author. Fax: +55-98-222-5135.

E-mail addresses: ajmc@elo.com.br (A.J.M. Caldas), jcosta@cpqgm.fiocruz.br (J.M.L. Costa).
}

communities. Dry periods that periodically hit the semi-arid North-east lead to human migration to the large centres, increasing the susceptibility of individuals to Leishmania chagasi infection and, in turn, the number of cases of the disease in this area, among them women of fertile age, with maternal-foetal implications (WHO, 1990; Silveira et al., 1993; Caldas et al., 2001).

In Brazil, four cases of VL in pregnant women have been reported, three of them from the Northeast (Moraes et al., 1995; Viana et al., 2001) and one from the North (Silveira et al., 1993). Despite an increase in the number of VL cases, the frequency of the disease is low among pregnant women. We present here the case of a woman followed up by our group, who was treated with amphotericin B with excellent outcome. 


\section{Case report}

Patient J.C.C., a 17-year-old girl from Cidade Olímpica (neighbourhood at the periphery of São Luís, MA), with a 2 month history of intermittent fever associated with cutaneous paleness, weight loss, vomiting and anorexia, sought medical assistance at an emergency service where she received symptomatic medication and blood transfusion.

With the signs and symptoms described above, the patient was seen at the Infectious and Parasitic Diseases Outpatient Clinic, Nucleus of Tropical Pathology, Federal University of Maranhão (UFMA). Physical examination revealed a regular general condition, hydration, weight loss, and hypostained mucosae $(++/ 4+)$, with small, motile, soft and painless ganglia being palpable in the submandibular and retrocervical chains. An enlarged liver $(4.5 \mathrm{~cm}$ from the right costal margin and $8.5 \mathrm{~cm}$ from the xiphoid appendix) with smooth borders, a soft palpable spleen $(6 \mathrm{~cm}$ from the left costal margin) and occupied Traube's space were observed. In addition, an increase in uterine volume suggestive of pregnancy was noted which was confirmed by the determination of human chorionic gonadotropin (105913 mIU/ $\mathrm{ml}$ ). Ultrasonography of the inferior abdomen showed foetal vitality. It was the first pregnancy of the patient, with a period of evolution of 3 months.

The diagnosis of VL was confirmed at MotherInfant University Hospital of UFMA by specific exams (indirect immunofluorescence, IIF - a titre of 1:320, and aspiration of bone marrow showed the presence of the amastigote forms of Leishmania), where she was admitted and treated with amphotericin B at the dose of $1 \mathrm{mg} / \mathrm{kg}$ per day for 14 days, with a good clinical response. Control exams were carried out during hospitalisation and after discharge (Table 1), and the electrocardiogram showed normal patterns. The patient was followed up after treatment at 3-month intervals for 12 months.

\subsection{Evolution}

Fever regressed on the third day of drug treatment and the other symptoms disappeared between the sixth and eighth day. The intradermal Montenegro reaction was positive 10 months after treatment. Cytokine determination revealed decreasing tumour necrosis factor and interleukin 10 levels after institution of treatment, while interferon gamma levels increased.

During the prenatal period the patient was submitted to the following serological exams: cytomegalovirus (IgM negative), lues (negative), German measles (IgG/IgM negative), toxoplasmosis (IgG/IgM negative), and anti-HIV 1 and 2 (negative), and received three doses of anti-tetanus vaccine.

The woman had a normal delivery and gave birth to a term (9 months of gestation) boy weighing $2485 \mathrm{~g}$, height $48 \mathrm{~cm}$, who did not present any abnormalities upon physical examination. The Leishmania IIF result in the umbilical cord was 1:80 and the ELISA result in peripheral blood was 1:268. During the 10 months clinical follow-up of the child, serology for Leishmania in peripheral blood was positive at 3 months (1:80) and negative after 6 months of life.

Many sections were collected from placenta and its annexa for hystological examinations. Microscopy revealed chorionic villi in the placental sections, which contained more stroma than usually observed for this gestational age, and an increase in the number of syncytial knots. In addition, various areas of chronic infarction as well as an increase in chorionic villus calcification were noted. Some arterial blood vessels of the villus trunks showed wall thickening. The amniotic epithelium was found to be simple and cylindrical, sometimes exfoliative, with apical nuclei. No alterations were observed for the extraplacental membranes or umbilical cord. No evidences of hematogenous placentitis were seen. The results of the final report were: placenta with delayed maturation, chronic infarction and ischemic alterations in placental villi, and the absence of Leishmania amastigotes.

\section{Discussion}

Low and Cooke (1926) reported the first Old World case of kala-azar in pregnancy which 
Table 1

Laboratory data obtained for the mother at the beginning, during and after treatment with amphotericin B (São Luís, Maranhão, Brazil, 2001)

\begin{tabular}{|c|c|c|c|c|c|}
\hline Exam & Before treatment & First week & Second week & 90 days & 180 days \\
\hline Red blood cells $\left(\times 1000\right.$ per $\left.\mathrm{mm}^{3}\right)$ & 3.14 & 3.93 & 2.35 & 3.11 & 3.82 \\
\hline Haemoglobin $(\mathrm{g} / \mathrm{dl})$ & 7.5 & 10.1 & 6.3 & 8.3 & 11.20 \\
\hline Hematocrit $(\%)$ & 21.6 & 30.3 & 19.3 & 26.0 & 33 \\
\hline Leukocytes $\left(\mathrm{mm}^{3}\right)$ & 3.4 & 4.0 & 5.0 & 6.3 & 11.8 \\
\hline Segmented cells $(\%)$ & 65 & 75 & 78 & 61 & 75 \\
\hline Lymphocytes (\%) & 30.1 & 21 & 17 & 28.6 & 18 \\
\hline Platelets $\left(\mathrm{mm}^{3}\right)$ & 96000 & 148000 & 148000 & 156000 & 160000 \\
\hline Oxalacetate transaminase (U/l) & 15 & ND & ND & 6 & 23 \\
\hline Pyruvate transaminase (U/l) & 28 & ND & ND & 5 & 16 \\
\hline Total bilirubin $(\mathrm{mg} / \mathrm{dl})$ & 0.48 & ND & ND & 0.48 & 0.49 \\
\hline Direct bilirubin $(\mathrm{mg} / \mathrm{dl})$ & 0.08 & & & 0.05 & 0.03 \\
\hline Erythrocyte sedimentation rate during the $1 \mathrm{st} \mathrm{h}(\mathrm{mm})$ & 59 & ND & ND & 35 & 23 \\
\hline Urea $(\mathrm{mg} / \mathrm{dl})$ & 12 & 17 & 13 & 12 & 10 \\
\hline Creatinine $(\mathrm{mg} / \mathrm{dl})$ & 0.5 & 1.1 & 2.5 & 0.9 & 0.40 \\
\hline Albumin $(\mathrm{U} / \mathrm{ml})$ & 3.1 & 3.9 & 2.0 & 3.4 & 2.53 \\
\hline Globulin (U/ml) & 5.3 & 3.7 & 1.6 & 3.2 & 1.20 \\
\hline Glycemia (mg/dl) & 79 & 79 & 79 & 78 & 77 \\
\hline Potassium (mEq/dl) & 3.1 & 3.1 & 3.1 & 3.0 & ND \\
\hline Sodium (mEq/dl) & 135 & 135 & 135 & 141 & ND \\
\hline Phosphorus (mg/100 ml) & 4.8 & 4.9 & 4.8 & ND & ND \\
\hline
\end{tabular}

$\mathrm{ND}$, not done.

occurred in Africa, with the child being born with signs and symptoms of the disease. Banerjee (1955) reported the case of a child born in England who manifested clinical signs and symptoms of laboratory confirmed kala-azar at 7 months of age. The mother of the child, who contracted the disease at 5 months of gestation, was returning to England from India where she had lived for several years.

Isam et al. (1992) reported the possible occurrence of two cases of congenital kala-azar in Sudan. In the first case, the child presented signs and symptoms of the disease at 7 months of age and died. Leishmania was detected in the liver, kidneys and thymus at autopsy. In the second case, parasites were found in the placenta in a 5-monthold foetus. Congenital transmission could not be confirmed in either case. Other authors (Niakundi et al., 1988; Yadav et al., 1989; Gradoni et al., 1994) have described cases of possible congenital kala-azar in the Old World similar to those reported by Isam et al. (1992).
In the New World, kala-azar in pregnancy is considered to be a rare occurrence in view of the number of cases reported in the literature. However, with the spreading of the disease in Brazil among urban and peri-urban areas where adults were generally not previously exposed to Leishmania, cases of pregnant women with kala-azar have been notified (Silveira et al., 1993; Moraes et al., 1995; Viana et al., 2001).

In Maranhão, Viana et al. (2001) reported two cases of kala-azar in pregnancy. In the first case, the mother had shown signs and symptoms of the disease since the seventh month of pregnancy, with the child being born at term. In the other case, the mother contracted kala-azar during the second month of pregnancy, with the child being born premature at 7 month. In both cases the diagnosis was confirmed after delivery by detection of Leishmania amastigotes in bone marrow aspirates. The mothers were treated after delivery with $N$ methylglucamine antimony $(20 \mathrm{mg} / \mathrm{kg}$ per day for 
20 days), and the children were clinically and serologically (IF) followed up for 6 months. Neither child showed clinical signs suggestive of the disease during this period and the IF tests were negative.

In the present case, no vertical transmission was observed, since the child followed up clinically and serologically for 10 months did not show any signs or symptoms of the disease, even though he was living in an endemic area. Serology (IF/ELISA) was positive from birth to 6 months of age and negative, thereafter, in agreement with cases from the State of Pará, Brazil, reported by Silveira et al. (1993). Anatomopathological analysis of the placenta did not reveal any parasites, thus suggesting the absence of Leishmania transmission from the mother to the infant.

Another important aspect to be discussed is the toxicity of the drugs used in the treatment of kalaazar to both mother and foetus. Pentavalent antimony compounds $\left(\mathrm{Sb}^{+5}\right)$ cross the placental barrier and might impregnate foetal nervous tissue, leading to severe syndromes of mental retardation (Marsden, 1985). However, Niakundi et al. (1988) recommended that, in areas endemic for kala-azar, pregnant women be treated with sodium stibogluconate at the dose of $20 \mathrm{mg} \mathrm{Sb}^{+5}$ per $\mathrm{kg}$ per day for 30 days.

Since amphotericin B has been recognised as a drug with leishmanicidal action but high toxic potential, therapeutic schemes (dosage, interval, total dose) have been modified over the years, a fact that led to progressive reduction and control of its toxicity and side effects (Mish et al., 1990; Giri, 1993; Thakur et al., 1999).

Based on the high rates of cure of kala-azar (93$100 \%$ ), the use of amphotericin B has been extended and its safe use in pregnant women without repercussions on the foetus has been reported (Mish et al., 1990; Thakur et al., 1993, 1999). Thakur et al. (1993) administered amphotericin $\mathrm{B}$ at the dose of $1 \mathrm{mg} / \mathrm{kg}$ per day for 20 days infused during a $2 \mathrm{~h}$ period to four pregnant women with kala-azar.

In Brazil, no reports on the treatment of pregnant women with kala-azar are available. In view of the variability of the proposed schemes, in the present case we opted for amphotericin B at the dose of $1 \mathrm{mg} / \mathrm{kg}$ per day for 14 consecutive days based on a study, which cure was obtained in $97.5 \%$ of non-pregnant patients with kala-azar (Carvalho, SFG, pers. inf.), demonstrating that amphotericin B, when used as the first-choice drug, leads to high rates of cure associated with a reduced total dose. In the present case, both the mother and the foetus showed a good response to treatment, with the foetus being followed up by abdominal ultrasonography.

\section{References}

Banerjee, D.N., 1955. Possible congenital infection in kala-azar. J. Indian Med. Assoc. 24, 433-435.

Caldas, A.J.M., Costa, J.M.L., Silva, A.A.M., Vinhas, V., Barral, A., 2001. Risk factors associated with asymptomatic infection by Leishmania chagasi in north-east Brazil. Trans. R. Soc. Trop. Med. Hyg. 95, 1-8.

Fundação Nacional de Saúde, 1996. Controle, Diagnóstico e Tratamento de Leishmaniose Visceral (Calazar) Brasilia: Ministério da Saúde, Brasil.

Giri, O.P., 1993. Amphotericin B therapy in kala-azar. J. Assoc. Phys. India 4, 91-93.

Gradoni, L., Gaeta, G.B., Pellizzer, G., Maisto, A., Scalone, A., 1994. Mediterranean visceral leishmaniasis in pregnancy. Scand. J. Infect. Dis. 26, 627-629.

Isam, I.A.E., Zijlstra, E.E., Ali, M.S., Ghalib, H.W., Satti, M.M.H., Eltoum, B., El-Hassan, A., 1992. Congenital kalaazar and leishmaniasis in the placenta. Am. J. Trop. Med. Hyg. 46, 57-62.

Low, G.C., Cooke, W.E., 1926. Congenital case of kala-azar. Lancet 211, 1209.

Marsden, P.D., 1985. Old drugs for new diseases. Rev. Soc. Bras. Med. Trop. 18, 187-198.

Mish, M., Biswas, U.K., Jha, D.N., Khan, A.B., 1990. Amphotericin B for second-line treatment of Indian kalaazar. Lancet 337, 926.

Moraes, C., Topyla, S.V., Paes, R.A.P., Cury, A.F., Tedesco, J.J.A., 1995. Leishmaniose visceral durante a gestação. Rev. Bras. Ginecol. Obstet. 17, 667-669.

Niakundi, P.M., Muigai, R., Were, J.B.O., Oster, C.N., Gachihi, G.S., Kirigi, G., 1988. Congenital visceral leishmaniasis: case report. Trans. R. Soc. Trop. Med. Hyg. 82, 564.

Silveira, F.T., Costa, D.P., Marques, K.C.C., Ishikawa, E., Shaw, J.J., Moraes, M.A.P., 1993. Leishmaniose visceral na gravidez: isolamento de L. chagasi da placenta humana. Rev. Soc. Bras. Med. Trop. 27 (Suppl I), 250.

Thakur, C.P., Sinha, G.P., Sharma, V., Barat, D., 1993. The treatment of kala-azar during pregnancy. Nat. Med. J. India 6, 263-269. 
Thakur, C.P., Singh, S.M., Hassan, R.K., Narin, S., Kumar, A., 1999. Amphotericin B deoxycholate treatment of visceral leishmaniasis with newer modes of administration and precautions: a study of 938 cases. Trans. R. Soc. Trop. Med. Hyg. 93, 319-328.

Viana, G.M.C., Nascimento, M.D.S.B., Viana, M.G.C., Burattini, M.M., 2001. Transmissão congênita do calazar. Rev. Soc. Bras. Med. Trop. 34 (Suppl I), 247.
Vieira, J.B.F., Coelho, G.E., 1998. Leishmaniose visceral ou calazar: aspectos epidemiológicos e de controle. Rev. Soc. Bras. Med. Trop. 31 (Suppl II), 85-92.

WHO, 1990. Control of Leishmaniasis. Technical Report Series, No.793.

Yadav, B.T.P., Gupta, H., Satteya, R., Kumar, R., Mital, V., 1989. Congenital kala-azar. Ann. Trop. Med. Parasitol. 83, $535-537$. 